\title{
DIALÉTICA DAS FONTES BIOBIBLIOGRÁFICAS: Wikipédia, Currículo Lattes e a (des)invenção dos sujeitos no campo científico
}

\author{
DIALECTICS OF BIOBIBLIOGRAPHIC SOURCES: Wikipedia, Curriculum \\ Lattes and the (dis) invention of subjects in the scientific field
}

\author{
Naira Christofoletti Silveira \\ Diogo Xavier da Mata² \\ Gustavo Silva Saldanha ${ }^{3}$
}

\begin{abstract}
RESUMO
0 texto é produto de pesquisa desenvolvida acerca das fontes de informação biobibliográfica e suas dinâmicas na Organização e Representação do Conhecimento, com foco na organização dos saberes, a saber, a pluralidade das formas e das experiências do conhecer. De natureza teórica, busca observar como se formam artefatos biobibliográficos sobre pesquisadores no contexto acadêmico e digital no Brasil. Explora-se neste texto dois dispositivos de informação distintos no plano empírico, o Currículo Lattes e a Wikipedia. Trata-se de uma dialética informacional a partir das práticas documentárias ou de práticas de escrita em rede sobre o sujeito pesquisador. Tomando a sociologia da ciência de Pierre Bourdieu, busca-se entender como se relacionam os agentes pela busca de reconhecimento no campo em que atuam. No plano da dialética, pela via das teorias de Mikhail Bakhtin, discute-se os modos distintos de enunciação, correspondentes às práticas informacionais distintas, uma documental e outra de escrita, percebendo as intencionalidades sociais para esta distinção na manipulação do enunciado. 0 foco da análise está no processo de individualização e de reconhecimento do pesquisador, a partir de um discurso biobibliográfico, sobrepondo o universo biográfico ao bibliográfico, e por fim como esta linguagem pragmática se comporta ao ser enunciada em diferentes locais de enunciação. Os resultados apontam para o questionamento do exercício discursivo como sistema de controle do que e do modo como se enuncia, livremente, igualitariamente e criticamente, o ser, biobibliograficamente, do sujeito pesquisador.
\end{abstract}

Palavras-chave: Biobibliografia. Wikipédia. Currículo Lattes. Dialética. Biopolítica acadêmica.

\begin{abstract}
The text is the product of research developed on the sources of bio-bibliographic information and their dynamics in the Organization and Representation of Knowledge, focusing on the plurality of ways of knowing. Of a theoretical nature, it seeks to observe how biobibliographic artifacts about researchers are formed. This text explores two different information devices at the empirical level. It is an informational dialectic based on documentary practices or network writing practices on the researcher subject. Taking Bourdieu's sociology of science, we seek to understand how agents relate to each other by seeking recognition in the field in which they operate. At the level of dialectics, through Mikhail Bakhtin's theories, we discuss the different modes of enunciation, corresponding to different informational practices, one documentary and the other of writing, realizing the social intentions for this distinction in the manipulation of the utterance. The focus of the analysis is on the researcher 's individualization and recognition process, based on a biobibliographical discourse, overlapping the biographical universe with the bibliographic one, and finally how this pragmatic language behaves when it is enunciated in different enunciation places. The results point to the questioning of the discursive exercise as a system of control of what and how it is enunciated, freely, equally and critically, the bio-biblical being of the researcher.
\end{abstract}

Keywords: Biobibliography. Wikipedia. Currículo Lattes. Dialectic. Academic biopolitics.

Artigo submetido em 13/05/2020 e aceito para publicação em 19/07/2020

1 Professora Adjunta no Departamento de Biblioteconomia Universidade Federal do Estado do Rio de Janeiro, Brasil. ORCID https:// orcid.org/0000-0002-0490-0052. E-mail: naira.silveira@unirio.br

2 Mestrando em Ciência da Informação Convênio Instituto Brasileiro de Informação em Ciência e Tecnologia e Universidade Federal do Rio de Janeiro, Brasil. ORCID https://orcid.org/0000-0002-2745-7196. E-mail: diogo.biblio@gmail.com

3 Professor assistente da Universidade Federal do Estado do Rio de Janeiro Docente permanente no Programa de Pós-Graduação em Ciência da Informação. Convênio Instituto Brasileiro de Informação em Ciência e Tecnologia e Universidade Federal do Rio de Janeiro, Brasil. ORCID https://orcid.org/0000-0002-7679-8552. E-mail: gustavosilvasaldanha@gmail.com 


\section{INTRODUÇÃ̃}

A materialidade dos registros biobibliográficos de pesquisadores funciona como espécie singular de dispositivo de controle e comunicação. Sua documentalidade exerce sobre a realidade social, a partir da realidade informacional, efeitos de controle bibliográfico e biopolítico. Há na historicidade bibliográfica uma ordem do bios, da atribuição de textos a pessoas, há na história do conhecimento registrado a figura de um sujeito. 0 discurso biobibliográfico funciona dentro de certos regimes cujo enunciado possua a função autoral, como por exemplo o cenário científico-acadêmico. Trataremos aqui como pesquisadores os autores do conhecimento científico.

0 pensamento bibliográfico no Brasil, principalmente a partir da segunda metade do século passado, passa a ser dominado pelo movimento bibliométrico (CRIPPA, 2019). Trata-se da passagem de uma tradição bibliográfica clássica da Modernidade - a contabilidade de registros do universo do biblion, como autor, título, termos - para uma bibliografia puramente estatística adotada para medidas de financiamento.

No ambiente formal da pesquisa científico-acadêmica, desde o desenvolvimento da comunicação científica em meados do XVII, a bibliografia se faz presente como modelo de comunicação, de controle, de organização e guia da literatura científica. 0 mundo pós Segunda Guerra percebe a ciência como índice de desenvolvimento e poderio entre as nações, transformando o trato, a gestão, da ciência índice esse mapeado e antecipado em 1934 por Otlet em seu Traité de Documentation. Os investimentos em pesquisas científicas demandam maior controle, o que gera a necessidade de informações sobre pesquisa e dados sobre e de pesquisadores para a tomada de decisão nos investimentos.

Esta nova configuração imposta por uma visão capitalista-mercadológica da ciência leva ao desenvolvimento de Sistemas de Informação Curriculares, como o Currículo Lattes no Brasil no final da década de 90 pelo Conselho Nacional de Desenvolvimento Científico e Tecnológico (CNPq). Preocupados com 0 registro de informações sobre pesquisadores, suas atuações, formações e produções, para a comunicação, gestão e memória da ciência brasileira. Atualmente, em rede com outros sistemas como 0 Open Research and Contributor ID (Orcid). 0 registro biobibliográfico no Currículo permite gerar indicadores que ordenam os sujeitos da comunidade acadêmica, em uma realidade classificada, entre produtivos e não produtivos. Neste cenário o sujeito se torna objeto, ele fala de si, pela lente do sistema, apenas responde ao que the é perguntado, ele é registro, é comparado, é medido. Essas inciativas, porém, são fruto de uma experiência histórica da documentalidade. 
No Brasil anterior a década de 90 muitos institutos de pesquisa publicavam os Quem é Quem (instrumento biobibliográfico) de pesquisadores referentes à sua área de pesquisa. Em sua grande maioria como se verifica em Mata (2017) esses instrumentos eram confeccionados por bibliotecários e documentalistas de cada instituição científica. 0 próprio Instituto Brasileiro de Bibliografia e Documentação (IBBD), criado em 1954 como unidade do CNPq, atualmente Instituto Brasileiro de Informação em Ciência e Tecnologia (IBICT), produziu em 1971 o Quem é Quem na Biblioteconomia e Documentação no Brasil. 0 dispositivo trazia uma lista dos profissionais e professores do campo, organizados alfabeticamente pelo nome do autor, sendo estes precedidos por uma divisão geográfica por estados. Sendo o IBBD pioneiro na sistemática bibliográfica e documentalista no Brasil, e na formação dos referidos documentalistas, pode-se inferir sua influência na confecção dos demais dicionários biográficos científicos produzidos pelo país.

Do outro lado, no espaço oposto, na dialética da discursividade biobibliográfica, podemos encontrar sistemas de liberdade enunciativa na rede. Por exemplo, temos a Wikipédia: a enciclopédia livre, como espaço discursivo onde, supostamente, podemos criar verbetes e descrevê-los. A "enciclopédia livre" começou formalmente em 2001. Na enciclopédia livre também podemos identificar uma cultura biobibliográfica acerca dos pesquisadores brasileiros.

Fruto de pesquisa desenvolvida nos últimos anos sobre a biobibliografia, fonte e discurso no âmbito da linguagem, a pesquisa apresentara, anteriormente, dentre outras coisas, uma abordagem quantitativa sobre o gênero dos verbetes biográfico de cientistas brasileiros na Wikipédia. À época, em 2016, 85\% dos verbetes biográficos da categoria Ciência no Brasil era referente a homens (SALDANHA; SILVEIRA; MATA, 2016). 0 que por si já demonstra uma grave discordância com os índices de sexo masculino e feminino encontradas na Plataforma Lattes. 0 movimento memorialístico da "Enciclopédia Livre" guardara anonimamente e, quase, invisivelmente, as figuras estereotipadas do machismo científico.

No ano de 2018, uma notícia é veiculada pelo jornal El Pais: "A mulher que inclui uma cientista por dia na Wikipédia" (MARTíN, 2018). A mulher, que trata o título da notícia, chama-se Jéssica Wade, mora em Londres, e seu esforço se deve a sua indignação em constatar quadro análogo ao encontrado por nós em 2016. Em 2018, quando a notícia foi veiculada, a cada 100 biografias da Wikipédia em inglês apenas 17 são referentes a uma mulher. 0 que seria $17 \%$ da quantidade de biografias. Note-se que em 2016 nas biografias científicas brasileiras chegamos ao resultado de 15\%, muito próximo. A inspiração de Jéssica está na norte-americana Emily Temple-Wood, ativista pela mesma causa. Percebe-se que a 
tendência brasileira não é exceção, parece ser a regra, passa-se por uma (des)invenção informacional das mulheres cientistas.

Na esteira destas questões, o desenvolvimento do estudo nos últimos anos aponta para 0 percurso de uma reflexão teórica que nos permite perceber a pragmática documentária biográfica no âmbito da ciência brasileira. A tessitura desta rede, mediada pela linguagem, concebe vários locais de enunciação distintos. Estes enunciados materializados, o próprio discurso biobibliográfico, em ambientes distintos, Currículo Lattes e Wikipédia, deixa transparecer as relações sociais simbólicas e de poder às quais se inserem. Esta constatação empírica, com suas evidências específicas, permite um desdobramento teórico-político e crítico das fontes de informação biobibliográficas contemporâneas.

Apoiados pela sociologia da ciência de Pierre Bourdieu (2004a; 2004b), busca-se contextualizar a disputa pela projeção de si em sistemas de informação, os agentes em busca de reconhecimento no campo científico. Em um segundo momento da reflexão teórica que se propõe buscamos nas ideias de Mikhail Bakhtin (2006) a proposta filosófica da linguagem em que um dado campo ideológico define seu próprio modo de orientação para a realidade e refrata a mesma realidade à sua própria maneira. Assim, um campo constrói sua própria função no complexo da vida social.

A partir dessas fontes, a pesquisa busca discutir a funcionalidade deste tipo discursivo acerca dos pesquisadores nos dois dispositivos citados. Trata-se aqui de refletir a dialética de suas enunciações, de seus comportamentos, de suas positividades. As condicionantes sócio-políticas que dominam nossa linguagem, limites contextualizantes da materialidade enunciativa que se explora, este é o ponto de inflexão de nosso debate. 0 embate dialético entre sistemas discursivos diferentes (como Plataforma Lattes e Wikipédia) na construção de uma realidade possibilitada pela linguagem da lógica biobibliográfica, constatando que de formas diferentes o poder da classificação nelas se exerce.

Os procedimentos metodológicos que adotamos, e também os percursos teórico-filosóficos, buscam contemplar as diversas etapas do complexo debate sobre a biobibliografia. 0 processo de individualização e de reconhecimento do pesquisador, a forma do registro de si em diferentes dispositivos informacionais, a organização biobibliográfica e seus efeitos econômico-políticos no campo da ciência, assim como a pragmática da lógica biobibliográficas são pontos neste tecido discursivo. 0 antagonismo entre Currículo Lattes e a Wikipédia oferecem para nós uma amplitude analítico-exploratória frutífera para o debate. Um pelo controle daquilo que se pode enunciar, o outro pela ideologia social que constrói com as mesmas dificuldades. 


\section{HORIZONTE HISTÓRICO DA BIOBIBLIOGRAFIA}

A revolução causada por Gutemberg gerou, no alvorecer da Modernidade, não só a solução da escassez de material bibliográfico, causou também uma proliferação feroz de textos que era necessário domar (BURKE, 2002). A necessidade de não se perder face a tantos textos obriga os modernos a desenvolver técnicas bibliográficas capazes de organizar esta nova realidade textual. É na Modernidade e na expansão da figura dos humanistas que, segundo André Araújo (2018), que aconteceram as primeiras concepções teóricas e metodológicas sobre a Bibliografia. Araújo (2018) cita, ainda, o primeiro repertório biobibliográfico da Era Moderna, o Liber de scriptoribus ecclesiasticis, publicada em 1494 por Johannes Trithemius (1462-1516).

É também na Modernidade que a bibliografia se posiciona enquanto sistema, enquanto disciplina, no entanto a prática, a arte, bibliográfica já estava presente no mundo antigo. Assim também podemos nos referir à biobibliografia, apesar desta nunca ter se consolidado como disciplina independente, sempre esteve calcada nas concepções da Bibliografia moderna. Como exemplos de biobibliografias anteriores à Modernidade, podemos citar os dicionários biográficos comuns na Idade Média. Além disso o catálogo de Calímaco (305-240a.c.) foi descrito por Witty (1958) como um biobibliographical catalogue raisonné.

0 modelo de dicionários biográficos como forma biobibliográfica de representar e organizar os sujeitos, contribui para nossa discussão acerca do reconhecimento/prestígio que este tipo de fonte pode conceder. Temos visto, dicionários biográficos ao longo não só da Modernidade, como na Idade Média, que classificam os sujeitos a partir da aplicação de adjetivos. Jerônimo de Estridão, sacerdote católico do século quarto, escreveu uma coleção de 135 pequenas biografias chamada De viris illustribus. Giovanni Boccaccio (1313-1375), escreveu De mulieribus claris, e Francisco Petrarca (1304-1374), famosa figura humanista, também compilou obra com esse título (De viris illustribus). A invenção de uma figura a ser lembrada, classificada como ilustre ou iluminada, faz parte de uma estratégia sóciopolítica na dialética da própria existência. Expressa bibliograficamente o reconhecimento de uma elite.

Estes nomes devem ser lembrados para que possam dar 0 exemplo para as futuras gerações, uma espécie de incentivo à imitação de uma moralidade ilustre narrada. É assim que Bernardini Scardeone (1560) se expressa em sua obra De antiquitate urbis Patavii e claris civibus Patavinis.

Além da ordenação moral, há uma questão de representação simbólica de um poderio absolutista com base na relação da quantidade de autores reunidos. Dito de outra forma, era possível pensar que 
obras biobibliográficas, com suas enormes listas de nomes de pessoas ilustres, eram capazes de representar simbolicamente o poder do soberano. La Croix du Maine (1584), em sua Bibliotheque, contenant les viés et les escrits de trois mille autheurs, fala ao rei que sua intenção era dupla ao compilar sua obra. A primeira intenção era conhecer e fazer-se conhecer por estes hommes doctes que ele está repertoriando, clássico objetivo de re-conhecimento de uma comunidade. 0 segundo motivo era fazer conhecer a grande vantagem e poder que floresciam destes homens doutos e par consequente à celuy qui est le roy (LA CROIX DU MAINE, 1584, não paginado). Demonstrando a concepção simbólica do discursar biobibliograficamente.

Outros muitos títulos da Gallica, biblioteca digital francesa, apresentam obras de biobibliografia em que seus títulos apresentam a figura de homens marcantes, ilustres, célebres e iluminados. Aqui estamos no centro da distinção biobibliograficamente registrada, uma ordem que de certa forma recorta o universo dos indivíduos, seleciona aqueles que a partir de um feixe de luzes, discursivamente alinhados, tal como propunha Michel Foucault (2008), se destacam. Estas constatações da Idade Moderna apontam para como o discurso biobibliográfico funcionava dentro de uma perspectiva da moral, das qualidades do indivíduo. Aponta-se para uma distinção social, realizada pela lógica biobibliográfica, operada pela transformação do sujeito em objeto.

No Manual de Fontes de Informação de Murilo B. da Cunha (2020), podemos verificar como as noções de biografias, de dicionários biográficos e de biobibliografias se relacionam no pensamento contemporâneo. Cunha (2020) trata do dicionário biográfico como uma espécie de fonte biográfica, e cita algumas biobibliografias como espécies de dicionários biográficos. Numa relação gênero-espécie, temos Fontes de Informação - Fontes Biográficas - Dicionários Biográficos - Biobibliografias.

0 discurso biobibliográfico contemporâneo, principalmente em sistemas como o Currículo Lattes e os modelos de Who's who perderam muito de sua expressão narrativa, caracterizando-se no geral como uma expressão entre dados e metadados. Neste ponto justifica-se o questionamento de Caproni (2018) "está acabando a era do homem do século XX, entendido como sujeito de ciência (e de história), e está começando a era do homem enquanto objeto?". 0 sujeito autor, aquele descrito pelo positivismo otletiano como a intencionalidade do escrito (OTLET, 1934), parece que vai sendo (re) significado, através dos indicadores métricos, também, dentro de uma dialética de discursos em rede. Ou seja, com a tomada bibliométrica da segunda metade do último século, a bibliografia toma outras configurações. 0 autor soberano dos dicionários biográficos, tal como criticado por Roland Barthes (2004), vai se rendendo às novas tecnologias e novas estratégias biopolíticas. 
0 cenário empírico que se desenha para nós na contemporaneidade é vasto em diferentes fontes na web de estudo e de discussão sobre o desenvolvimento de canais biobibliográficos, no entanto escolhemos dois tipos que exemplificam bem a dialética entre as fontes biobibliográficas do campo científico contemporâneo. 0 Currículo Lattes enquanto sistema oficial, necessário no meio acadêmico e altamente estruturado, a Wikipédia um ambiente coletivamente construído, não obrigatório e com uma estrutura menos pré-determinada.

0 Currículo Lattes é um sistema de currículos em rede, possui como cabeçalho de cada registro o nome próprio de um sujeito. É instrumento fundamental na consolidação de informações para a avaliação e gestão da ciência no Brasil. Um dos principais objetivos desta plataforma é a padronização dos currículos de pesquisadores das diversas áreas do conhecimento. 0 Currículo é exigido em diversas atividades/rituais acadêmicos como em uma seleção de pós-graduação ou de docência, sua atualização também é requerida para que se possa efetuar diversos tipos de avaliações, como a avaliação de um programa de pós-graduação. Esse aspecto muito administrativo de controle e avaliação das informações biobibliográficas da pesquisa brasileira. Diminui demasiadamente as funções bibliográficas de comunicação e guia por um conjunto de conhecimento registrado.

A faceta de representação, organização e recuperação que um sistema como a Plataforma Lattes têm em potencialidade é significativamente diminuída pelas suas apropriações econômicopolíticas. Essa ausência de mérito tem início, ao nosso ver, em duas situações: primeiro, a Plataforma não foi pensada diretamente para este objetivo; segundo, a "uberização" dos serviços biobibliográficos científicos causa o registro de uma massa de informações "cruas" sem o devido tratamento bibliográfico. Fontes de informação como os “Quem é Quem” (Who’s who) eram no decorrer do século XX produzidos por documentalistas das instituições referências em alguma área do saber. Estes instrumentos informavam, de forma padronizada e bibliograficamente tratada, uma gama de dados como: nome, contato, endereço, instituição, projetos de pesquisa, trabalhos apresentados em eventos, publicações em periódicos e bolsas de estudo recebidas. Confirmando no Brasil um protagonismo de documentalistas neste campo.

A Wikipédia é uma enciclopédia livre e construída coletivamente através de edições realizadas por colaboradores voluntários, apesar de ser entendida como uma enciclopédia "livre" não significa que esta não possua regras. Peter Burke (2012) analisa a Wikipédia como um "carro-chefe" da "ciência cidadã", mas indica ser muito difícil analisá-la a partir da história social, devido a esta aos verbetes anônimos desta experiência enciclopédica, e também de sua mutabilidade (BURKE, 2012). Apesar 
da Wikipédia possuir características que a distanciam da forma habitual de construção, organização e disseminação de conhecimento, não podemos deixar de reconhecer sua relevância como fonte de conhecimento compartilhado e erguido através dos próprios usuários.

Apesar da distância dos propósitos das ferramentas biobibliográficas apontadas em nosso campo empírico, faz-se importante observar que carregam uma "variável" comum, central na formação do sujeito moderno: o nome próprio. Como Saldanha e Silveira (2016) observam, a relevância da condição de fundo filosófico dos nomes próprios passa pelos âmbitos dos estudos socias (entre política, sociologia e antropologia) até abordagens teóricas e aplicadas da organização do conhecimento. Assim, o nome próprio foi objeto dos questionamentos de Platão, de Foucault, de Barthes, de Derrida, para citar algumas fontes de reflexão sobre o seu poder simbólico. Ritualístico e carregado de poder, o nome próprio é a chave de entrada no universo biobibliográfico, revelando já em sua vitrine os dilemas de gênero e de classe, abrindo para nossa reflexão a possibilidade dialética de discutir a biobibliografia como objeto clássico de uma teoria crítica em Ciência da Informação.

\section{DAS DISPUTAS SIMBÓLICAS À DOCUMENTALIDADE E/OU A ESCRITA BIOGRÁFICA NO CAMPO CIENTÍFICO: DISCUSSÃO E DIALÉTICA}

0 homo academicus, analisado por Bourdieu (2013), figura representada por um nome, fruto de um processo de lutas simbólicas - uma economia permanente (BOURDIEU, 2011; 2012), onde se estabelece o seu modo de agir, de publicar, de falar sobre si e sobre os outros. Percebemos, inicialmente, que a luta por uma "partegênese da ciência", na visão de Bourdieu (2004a), ou seja, de um longo e contínuo processo de tentativa de autoperpetuação do campo científico tem relação objetiva, central, com a materialização de um conjunto de instrumentos de reconhecimento do poder simbólico do sujeito dentro de sua episteme, dentro do seu espaço institucional. Essas condições foram mapeadas pelos estudos bourdieusianos, em diferentes contextos, mas o que percebemos é a estrutura simbólico-material do discurso biobibliográfico, um dos mais potenciais recursos de afirmação do sujeito epistêmico em seu locus.

No entanto, quando confrontamos, ainda com Bourdieu (2004a), os sociais da ciência, bem como os usos científicos do mundo social, percebemos a confluência de relações complexas, de distinções multiplicadas nos mais diferentes e abertos níveis de desigualdade, de deslocamentos e de formalizações de hierarquias previstas no tecido social e, por fim, de reprodução de padrões segurados 
pelo poder simbólico. As dinâmicas de distinção presentes no discurso social demonstram aqui o jogo da pragmática entre ciência e sociedade.

Na esteira do pensamento sociológico de Pierre Bourdieu (2004a), podemos conceber a ciência como um campo de produção cultural. 0 campo, na leitura bourdiesiana, se caracteriza pela luta simbólica entre agentes e instituições que produzem, reproduzem ou difundem seus produtos culturais, como a obra de arte no campo artístico, um romance no campo literário, ou um artigo científico no campo da ciência.

A partir da filosofia da linguagem, podemos compreender com Bakhtin (2006) o modo como a construção social do sujeito (auto)biobibliografado se concebe. Como signo ideológico, a palavra incluindo o nome próprio - representa uma materialidade e estabelece um contexto de "ubiquidade social". Na visão bakhtiniana, ela penetra diretamente em todas as relações da vida dos indivíduos, nas conexões ideológicas, nos mais fortuitos e simples modos de ser da vida cotidiana, bem como na macropolítica de cada localidade. Tecidas a partir da "multidão de fios ideológicos", servem então como trama para as mais distintas formas de relacionamento social.

Por esse poder de "ubiquidade social", a palavra, segundo Bakhtin (2006, p. 40), representa um "indicador" central para a imobilidade e as transformações sociais. A palavra, fruto da linguagem, permite a identificação dos sistemas ideológicos que nascem, mesmo sem forma avançada. Assim, a linguagem leva-nos à identificação dos lentos acúmulos quantitativos de mudanças em cada sistema ideológico, registrando fases transitórias e efêmeras.

A palavra se torna, assim, o que se pode chamar, dentro de uma psicologia social, segundo o léxico bakhtiniano (BAKHTIN, 2006, p. 40), uma forma de perceber o sujeito "metafísico" ou "mítico", configurando o que em geral se chama de "alma coletiva", ou "inconsciente coletivo", ou "espírito do povo". Essa psicologia é, antes uma psicologia do "corpo social" que não se situa em nenhum ponto interior do sujeito em estado de comunicação. Ao contrário, segundo Bakhtin (2006), essa manifestação dada pela palavra é inteiramente projetada ao exterior: está em ato, sempre na superfície, na troca, na materialidade.

Deste modo, todas as relações de produção e da demarcação da estrutura sócio-política estão conectadas aos contatos verbais entre indivíduos, suas formas de comunicação, em contextos como trabalho, vida política. A criação ideológica é, pois, fruto e dependente da palavra. Uma psicologia do corpo social, de acordo com Bakhtin (2006, p. 41), é fundada na comunicabilidade que está presente nos diferentes espaço-tempos de criação ideológica, como conversas de corredor, trocas de opinião no teatro, reuniões sociais diversas, em meio à reconstrução dos contextos de regulamentação social. 
0 método buscado pelo horizonte bakhtiniano é, pois, construído a partir das seguintes regras:

1. Não separar a ideologia da realidade material do signo (colocando-a no campo da "consciência" ou em qualquer outra esfera fugidia e indefinível).

2. Não dissociar o signo das formas concretas da comunicação social (entendendo-se que 0 signo faz parte de um sistema de comunicação social organizada e que não tem existência fora deste sistema, a não ser como objeto físico).

3. Não dissociar a comunicação e suas formas de sua base material (infra-estrutura). (BAKHTIN, 2006, p. 43)

Se Bakhtin (2006) nos fala de todas as formas de comunicação dentro dos sistemas de criação ideológica, quando nos aproximamos da construção do mundo da escrita e do mundo bibliográfico, deparamo-nos com o imenso e complexo império de regulações, de controle e de vigilância estabelecida pelo poder da palavra registrada. Aqui, o poder se torna uma máquina de enredamento social.

Essa materialidade da qual nos fala a obra bakhtiniana nos leva ao encontro com o Bourdieu (1983) "filósofo da linguagem", ou "sociólogo da cultura pela via da linguagem". Como o pesquisador francês aponta, em sua "economia das trocas linguísticas, pode-se falar no desenvolvimento das práticas de reprodução a partir de uma língua dita legítima, das relações de comunicação como relações de força simbólica e o discurso como um valor. A competência linguística é, pois, inerente à posição daquele que fala na estrutura social.

Desta maneira, no discurso bourdieusiano, quem fala nunca é a palavra, o discurso, mas a pessoa social. A força do discurso e da aplicação da palavra depende da autoridade de quem fala. É nesse sentido que as fontes biobibliográficas nos convocam para conhecer e discutir o corpo social de quem fala sobre si e sobre o outro, a partir do nome próprio e dos feitos da criação ideológica dos regimes de controle e de visibilidade biobibliográficos.

\section{UM CAMPO EMPÍRICO BIOBIBLIOGRÁFICO EM EBULIÇÃO: CURRÍCULO LATTES E AS BIOGRAFIAS CIENTÍFICAS BRASILEIRAS NA WIKIPÉDIA}

“Em outros termos, os discursos não são apenas (a não ser excepcionalmente) signos destinados a serem compreendidos, decifrados; são também signos de riqueza a serem avaliados, apreciados, e signos de autoridade a serem acreditados e obedecidos" (BOURDIEU, 2008, p. 53). Se o campo científico é um campo de lutas simbólicas, a linguagem determina um poderoso arsenal. Existe no campo científico, local de relação entre os agentes, mecanismos de afirmação-fixação dos enunciados acerca do sujeito. Estes dispositivos biobibliográficos são expressão da figura do sujeito 
pesquisador em suas facetas, socialmente aceitas e politicamente estruturadas, sejam elas de biografia pessoal ou acadêmica, de uma atuação institucional ou de uma produção bibliográfica científica. Além disso, determinam a relação entre autor e texto, como uma espécie de registro de propriedade. Exibição simbólica a partir de uma melhor performance simbolicamente instituída como científica. Toda relação de propriedade, assemelhada à noção de capital, geram uma realidade econômico-simbólica de acumulação, de prestígio e de reconhecimento entre os pares. Esta é a expressão da formação de uma elite. Ora, seria a materialidade biobibliográfica a própria documentalidade de um capital científico (em forma de enunciados que afirmam sua posição, sua produção, seus títulos, suas credenciais). Também funciona como espécie de fio condutor ao colocar os indivíduos em rede com outros, da mesma forma sujeitados a um sistema de descrição igual para todos (os mesmos descritores são aplicados aos diversos indivíduos). Nesta relação entre capital individual e coletivo, acontecem as distinções, as seleções, as classificações, que determinam aquilo que deve constar, aquilo que deve ser dito. Por isso que acompanhamos Barthes (1980, p. 14) em: "Mas a língua, como desempenho de toda linguagem, não é nem reacionária, nem progressista; ela é simplesmente: fascista; pois o fascismo não é impedir de dizer, é obrigar a dizer". A linguagem legislação, a língua o código, ousamos dizer: A biobibliografia é 0 código de uma sociologia do autor.

A realidade da documentalidade, sua performance entre e nos mais diferentes campos, aparentemente distantes, pode ser compreendida em suas contradições a partir do papel da linguagem que a tece e a multiplica. Logo, tal linguagem é dialética em sua forma de produção e de recepção. Partindo de Bakhtin (2006), podemos perceber que a concretude onde dorme a documentalidade dos estudos informacionais é, pois, a própria concretude da linguagem. É sob o signo da palavra, conforme o discurso bakhtiniano nos aponta, que se formam e se consolidam as estruturas de uma filosofia burguesa.

Como aponta o filósofo da linguagem, "a essência deste problema, naquilo que nos interessa, liga-se à questão de saber como a realidade (a infra-estrutura) determina o signo, como o signo reflete e refrata a realidade em transformação." (BAKHTIN, 2006, p. 40). Esse movimento é objetivamente observável nas infraestruturas dos regimes biobibliográficos.

0 programa de estudo de Bakhtin (2006) contribui para entendermos o papel produtivo e a natureza social da enunciação. A chamada "economia das trocas linguísticas" bourdieusiana encontra na concretude dialética bakhtiniana uma convergência clara de análise e de crítica. Essa aproximação pode ser pontuada na clássica visão de Bakhtin (2006) em que sem signos fica impossibilitada a ideia 
de ideologia. Logo, a simbolização do princípio de necessidade é socialmente estabelecida como um produto ideológico. 0 signo, então, se converte em um dado objeto físico, refletindo e refratando outras realidades.

A construção social da enunciação do eu se posiciona na expressão de fatos sócio-ideológicos, sejam estas enunciações dadas em um dispositivo oficial de controle da produção científica, como 0 Currículo Lattes, ou em dispositivos que supõem uma certa liberdade e equidade de escrita, como a Wikipédia. A permanência dos nomes próprios na documentalidade bibliográfica, funcionam como dispositivos embebidos em ideologia transmitida e comunicada através dos signos (BOURDIEU, 2008).

Don Fallis (2008) discutiu, em um plano teórico, a necessidade de reconhecimento de uma certa "epistemologia da Wikipédia" (2008). Neste artigo apresenta uma noção da enciclopédia, de uma maneira geral, objetivando refletir uma epistemologia do próprio modelo wiki de repertoriar 0 conhecimento, no sentido morriniano, de articular as visões sobre a amplitude aberta e heterogênea dos saberes. Para Fallis (2008), a Wikipédia tem hoje grande impacto na maneira como as pessoas reúnem informação sobre o mundo, sendo ainda seu conteúdo considerável em termos de confiabilidade.

Tendo em vista observações diretas da plataforma wiki e as correlações com a experiência biobibliográfica da Plataforma Lattes, não deixamos de reconhecer e de abordar a Wikipédia como locus de construção de imensos potenciais de liberdade. Por ser construída coletivamente, tende a se concretizar cada vez mais como uma importante parte de nossa memória. Sob o tom dialético bakhtiniano, bem como sob a visão crítico-analítica do campo científico em Bourdieu (2014a,b), apontamos, no entanto, para a necessidade de uma crítica da organização do conhecimento wiki ali em curso. Enquanto estrutura ideológica, seus efeitos socioideológicos podem resultar em abordagens contrárias à proposta "livre": circular menos o conhecimento, e mais as categorias hegemônicas; repertoriar e "trazer à memória" menos a pluralidade dos sujeitos e seus construtos, e mais as mentalidades "vencedoras".

O Currículo Lattes é documento intimamente ligado ao próprio pesquisador, tem inclusive relações institucionais com a Receita Federal, as páginas biográficas na Wikipédia não são necessariamente criadas e escritas por aqueles de quem elas falam. Guardam entre si, semelhanças e diferenças. Uma destas semelhanças é a centralidade do nome próprio, tanto o Currículo quanto os verbetes biográficos da Wikipédia estão organizados pelos nomes próprios, eles são seu principal ponto de acesso. No entanto, há uma característica que nos chama atenção o conteúdo muito próximo entre os dois cenários discursivos. Mesmo a Wikipédia busca apresentar uma lista da produção bibliográfica do pesquisador. 0 
que aponta para uma complexa reflexão acerca do que melhor representa um pesquisador. Traduzindose na inquietação acerca daquilo que podemos falar, aquilo que devemos lembrar acerca de uma pessoa. Não seria esta semelhança um fato sócio-ideológico de homogeneização, linguisticamente operacionalizado através de uma discursividade biobibliográfica? Esta é a reflexão de toda uma vida de pesquisa, discussão e reflexão, mas se nos é permitido uma resposta, diríamos que sim.

A representação e organização legítima operada pelas biobibliografias, no campo de disputas simbólicas da ciência, não se sustentam de forma natural. Ela se dá no nível de produção e reprodução de uma forma de discurso de si e do outro legitimado. A própria luta entre os pesquisadores no jogo da representação do seu ser na dinâmica econômica-simbólica do campo científico, perpetua e legitima esta forma de representação e ordenação dos atores. Em outras palavras, a própria dinâmica de classificação, produzindo uma classe superior, outorgada pelo poder da representação dos dispositivos biobibliográficos contribuem para a reprodução mesmo em outros espaços do mesmo discurso de si e do outro. Essa forma de representação passa a ser defendida pelos dominantes como uma espécie de preservação e manutenção de seu capital acumulado (BOURDIEU, 2008).

A "ubiquidade social" referente ao nome próprio no universo da biobibliografia indica a possibilidade de se pensar uma sociologia de seus usos. A materialidade dos nomes próprios, seja no Currículo Lattes ou na Wikipédia, encontra-se enredada no jogo do poder, da dominação de classes. A própria determinação classificatória que geralmente acompanha estas listas de nomes comprova a determinação social que se faz deles, forma de produção e reprodução de um existir, de um agir, legítimo, aceito, considerado pela comunidade. Assumindo, portanto, o nome próprio, sua descrição e as possíveis classificações que fazem dele um instrumento legítimo, por ser legitimado, da dominação política.

Dominação que tende a levar em consideração as regras do jogo que a diversidade de campos impõe. A dialética que cada espaço de representação instaura, de forma diferenciada, na realidade simbólica dos atores, deve ser levada em consideração. E é justamente nesse ponto de diferenciação que encontramos a proximidade de dois discursos distantes, como o Lattes e a Wikipédia. Seus jogos de dominação se exercem sutilmente de forma diferenciada, como relatado. A relação entre discurso e mercado é o que produz o valor dos enunciados. 0 preço, ou o valor particular, que se atribui a cada discurso é produto de uma interação entre os atores do campo que sejam capazes de produção e apreciação daquele tipo de mercadoria. Há estratégias de construção do discurso com base naquilo que seus interlocutores socialmente valoram majoritariamente (BOURDIEU, 2008). 
Todas essas concepções sociológicas que regem as economias das trocas linguísticas expõem a reflexividade dos dispositivos biobibliográficos, e nos ajudam a pensar a sua dinâmica enquanto jogo de disputas de reconhecimento e produção de valor. 0 mercado da ciência tem seus pontos de valorização da trajetória acadêmica que estruturam socialmente a percepção de sucesso, notoriedade, ou fracasso, apagamento, do pesquisador. 0 discurso biobibliográfico legitimado por suas classes dominantes, satisfeitas com seu acúmulo de capital, está valorado socialmente de fora para dentro. Seus objetos, os próprios pesquisadores, buscam cada vez mais a produção de um discurso mais valorizado pela cotação social que o próprio mercado em que se inserem postula. Exigindo pela dinâmica social da dominação; de valoração e reconhecimento determinada trajetória biográfica.

\section{CONSIDERAÇÕES FINAIS}

0 foco biobibliográfico nos condiciona a pensar a construção de um modelo de pensamento que se instaura na Antiguidade e, sob regimes distintos, desenvolve-se e desenvolve a própria Modernidade (o duplo criador e criatura do paradigma gutemberguiano e sua prensa na construção do mundo moderno). Temos com o espelho biobibliográfico um reflexo das formas como os sujeitos são visibilizados e operam no poder do nome próprio dentro da realidade social dos últimos 500 anos.

A condição política dos rastros biobibliográficos é fato comum, de todo modo, de tal percurso arqui-milenar, para aquém da Modernidade. A intencionalidade dessa construção é demonstrada pela força do papel da biopolítica das bibliografias enunciadas a partir do nome próprio do sujeito e sua bagagem produzida textualmente, sua lista de "feitos gráficos".

0 resultado do percurso das fontes bibliográficas é sua absorção ao plano métrico das ações do sujeito. É justamente a partir da biobibliografia que a biopolítica dos corpos no ambiente acadêmicocientífico se estabelece. 0 controle se dá em um movimento de dentro para fora, e de fora para dentro. Essa circulação pode ser vista com o confronto de fontes distintas, mas com algumas semelhanças clássicas do universo das fontes biobibliográficas (a começar pelo arranjo autoria - obras da autoria). Eis 0 que a relação entre Wikipédia e Currículo Lattes nos permite.

Ao observar essas duas fontes biobibliográficas percebemos as condicionantes sociais da biopolítica biobibliográfica. Trata-se de perceber essas ferramentas como fatos socioideológicos, assim como nos aponta o legado bakhtiniano. Ambas postulam um regime de controle com foco na medição dos espíritos pelos seus feitos (quantitativos) gráficos, conjugando a existência a partir da materialidade 
linguística da produção bibliográfica documentada em canais com políticas pré-estabelecidas, porém já apropriadas pela superestrutura do capital. Os perfis do Currículo Lattes e aqueles que podem ser, de fato, "perfilados" na lista de cientistas da Wikipedia revelam todos os problemas de uma dialética do mundo social, como os dilemas de gênero, classe e raça, revelando do que o léxico bourdieusiano tão bem chama de "distinção".

\section{REFERÊNCIAS}

ARAUJO, Andre Vieira de Freitas. Sobre a eminência e o eco da Bibliografia: nos rastros do método bibliográfico gesneriano e dos fundamentos do campo. 2018. Tese (Doutorado em Cultura e Informação) - Escola de Comunicações e Artes, Universidade de São Paulo, São Paulo, 2018. Disponível em: https://teses.usp.br/teses/disponiveis/27/27151/tde-13092018-144446/pt-br.php. Acesso em: 30 abr. 2020.

BAKHTIN, M. Marxismo e filosofia da linguagem: problemas fundamentais do método sociológico da linguagem. São Paulo: Hucitec, 2006.

BARTHES, Roland. A aula: aula inaugural da cadeira de semiologia literária do Colégio de França. São Paulo: Cultrix, 1980.

BARTHES, Roland. A morte do autor. In: BARTHES, Roland. 0 rumor da língua. São Paulo: Martins Fontes, 2004. p. 57-64.

BOURDIEU, Pierre. Os usos sociais da ciência: por uma sociologia clínica do campo científico. São Paulo: Editora Unesp, 2004a.

BOURDIEU, Pierre. Para uma sociologia da ciência. Lisboa: Edições 70, 2004b.

BOURDIEU, Pierre. A Economia das trocas linguísticas: 0 que falar quer dizer. 2. ed. São Paulo: Edusp, 2008.

BOURDIEU, Pierre. Economia das trocas linguísticas. In: BOURDIEU, Pierre. Bourdieu Sociologia. São Paulo: Ática, 1983. p.156-183.

BOURDIEU, Pierre. A economia das trocas simbólicas. São Paulo: Perspectiva, 2011.

BOURDIEU, Pierre. A distinção: crítica social do julgamento. 2. ed. rev. Porto Alegre: Zouk; São Paulo: EDUSP, 2012.

BOURDIEU, Pierre. Homo academicus. Florianópolis: Ed. da UFSC, 2013.

BURKE, Peter. Problemas causados por Gutenberg: a explosão da informação nos primórdios da Europa moderna. Estudos Avançados, São Paulo, v. 16, n. 44, p. 173-185, Apr. 2002. Disponível em: https://www.scielo.br/scielo.php?script=sci_arttext\&pid=S0103-40142002000100010. Acesso em: 10 maio 2020. 
BURKE, Peter. Uma história social do conhecimento II: da Enciclopédia à Wikipédia. Rio de Janeiro: Zahar, 2012.

CAPRONI, Attilio Mauro. Sapere Aude (dizia Kant): a bibliografia, uma ordem do discurso do século XXI? Informação e Informação, Londrina, v. 23, n. 2, p. 04-13, maio/ago. 2018.

CRIPPA, Giulia. 0 desenvolvimento e 0 entrelaçamento entre bibliografia, bibliometria e política no Brasil. Em questão, Porto Alegre, v. 25, p. 14-38, Edição Especial V Seminário Internacional A Arte da Bibliografia, 2019.

FALLIS, Don. Toward an Epistemology of Wikipedia. Journal of the American Society for Information Science and Technology, v. 59, n.10, p. 1662-1674, 2008.

FOUCAULT, Michel. A arqueologia do saber. Rio de Janeiro: Forense Universitária, 2008.

INSTITUTO BRASILEIRO DE BIBLIOGRAFIA E DOCUMENTAÇÃO. Quem é quem na Biblioteconomia e Documentação no Brasil. Rio de Janeiro: IBBD, 1971.

LA CROIX DU MAINE, François Grudé. Premier volume de la Bibliothèque du sieur de La Croix Du Maine , qui est un catalogue général de toutes sortes d'autheurs qui ont escrit en françois depuis cinq cents ans et plus jusques à ce jour d'huy... Paris: 1584

MARTín, Bruno. A mulher que inclui uma cientista por dia na Wikipédia. El País, Madrid, 18 jul. 2018. Disponível em: https://brasil.elpais.com/brasil/2018/07/05/ciencia/1530788593_072320.html. Acesso em: 30 abr. 2020.

MATA, Diogo Xavier da. A Ordem do Discurso Biobibliográfico: uma reflexão sobre a construção social entre as fontes de informação biográfico-científicas às apropriações em rede. 2017. Trabalho de Conclusão de Curso (Bacharelado de Biblioteconomia) - Escola de Biblioteconomia, Universidade Federal do Estado do Rio de Janeiro, Rio de Janeiro, 2017.

OTLET, Paul. Traité de Documentation. Mundaneum: Bruxelas, 1934.

SCARDEONE, Bernardini. De antiquitate urbis Patavii e claris civibus Patavinis libri tres, em classes quindecim distintas. Ejusdem apêndice de sepulchris insignibus exterorum Patavii jacentium. Basiléia: Episcopium, 1560.

SALDANHA, Gustavo S.; SILVEIRA, Naira C. Own name in Knowledge Organization Epistemology: a philosophical-theoretical debate. Knowledge Organization, v. 43, p. 265-278, 2016.

SALDANHA, Gustavo S.; SILVEIRA, Naira C.; MATA, Diogo X. da. Breves cenários dialéticobiobibliográficos: liberdade, expressão e materialidade entre a Wikipédia e o Currículo Lattes (ou "A Wikipédia como fato socioideológico"). In: CONGRESSO CIENTÍFICO BRASILEIRA DA WIKIPÉDIA, 1., 2016, Rio de Janeiro. Programação. Rio de Janeiro: CCBWIKI, 2016. Trabalho apresentado oralmente, não publicado.

WITTY, Francis J. The Pínakes of Callimachus. Library Quarterly, Chicago, v. 28, n. 2, p. 132-136, abr. 1958. 